\title{
Hypericum Perforatum Extract Modifies Serum and Tumoral Redox Status and Nitric Oxide Metabolites in Mice
}

\author{
Burcu Menekse Balkan \\ Department of Biochemistry, Faculty of Veterinary Medicine, \\ Burdur Mehmet Akif Ersoy University, 15030, Burdur, Turkey \\ E-mail: bmabalkan@mehmetakif.edu.tr
}

\begin{abstract}
This research was founded by Burdur Mehmet Akif Ersoy University Scientific Research Projects Unit (Project Number: 0528-YL-18) (Sponsoring information)
\end{abstract}

\author{
Presented at 4th International Congress on Advances in Bioscience and Biotechnology (ICABB), \\ September 30, 2020
}

\begin{abstract}
Plant extracts with antioxidant efficacy and/or suppressive activity on nitric oxide (NO) production are highly being used as supplements by cancer patients. Despite very high concentrations of NO can kill malignant cells; NO can also propagates cancer growth even at supraphysiological levels. Hence, discovery of safe compounds diminishing NO production may be beneficial in reducing cancer progression. Hypericum extracts are shown to exert redox-active efficacies and to reduce NO production in non-malignant conditions; but it is not studied in terms of modifying systemic and tumoral redox status, nitrite and nitrate concentrations. In this study, we showed that Hypericum perforatum extracts significantly reduces intratumoral levels of nitrite and nitrate in solid tumors formed by Ehrlich ascites carcinoma cells. These results may suggest that Hypericum perforatum extracts may act as efficient adjuvants for malignancies which growth are highly influenced and propagated with NO.
\end{abstract}

Keywords: Hypericum perforatum; total oxidant status; total antioxidant status; nitric oxide; nitrite; nitrate

DOI: $10.7176 / \mathrm{JSTR} / 7-05-05$

\section{Introduction}

Cancer remains to be one of the major causes of death worldwide. While the efforts to develop new anticancer agents are huge, easily applicable and cost-effective phytochemical agents may act as beneficial adjuvants in managing this deadly disease. Hypericum perforatum is a plant which is widely explored in managing cancer and changes production of reactive oxygen species (ROS) in tumoral tissue and contains active antineoplastic compounds such as hyperforin, hyperoside, hypericin, pseudohypericin and rutin (Hohmann et al. 2015; Huntosova et al. 2017; Yang et al. 2017; Menegazzi et al. 2020). Noteworthy, extracts of Hypericum perforatum exert significant antioxidant effects and protects neurons against oxaliplatin toxicity while not sparing, even killing colon cancer cells making it ideal to employ as an adjuvant in cancer treatment (Cinci et al. 2017). With its relatively low oxidation and reduction potential, hypericin harbors both electron donating and accepting features causing it to act as both a reducing and an oxidizing agent (Blank et al. 2001). Therefore, hypericin can compete as an acceptor of electrons from oxidation/reduction reactions generating its excitation energy for biological activities from physiological oxidation-reduction reactions (Blank et al. 2001). Hypericum perforatum extracts inhibit JAK2/STAT-1 activation cascade and the subsequent stimulation of iNOS (inducible-Nitric Oxide Synthase) expression in lung and colon epithelia (Tedeschi et al. 2003). Hence, this extract can be a good candidate for manipulating intratumoral levels of nitric oxide (NO). Supraphysiological levels of NO and their products are tolerated by malignant cells and even used as autocrine and paracrine mediators to propagate self-growth.

42 | $\mathrm{P}$ a g e

www.iiste.org 
During initiation of carcinogenesis, NO can delay cell cycle progression, allowing for erratic DNA repair that stimulates the accumulation of mutations and causing tumor heterogeneity (Khan et al. 2020). During progression of cancer, low to moderate (even supraphysiological) levels of NO origined from malignant and endothelial cells can induce angiogenesis, epithelial-to-mesenchymal transition and an aggressive biology (Khan et al. 2020). A well-delineated feature by which NO modifies cell functions is the posttranslational modification of cysteine thiols in target proteins by a biochemical phenomenon defined as Snitrosylation (Iyer et al. 2014). Studies increasingly revealed S-nitrosylation as the NO's primary regulatory mechanism in their respective systems, which modifies cell-death and -survival pathways in versatile tissues (Iyer et al. 2014). For instance, NO-mediated S-nitrosylation of the antiapoptotic Bcl-2 protein hinders its ubiquitination and proteasomal degradation, leading to inhibition of apoptosis, which is the primary event involved in the malignant transformation of benign lung epithelia following long-term exposure to carcinogens (Azad et al. 2010).

The dual nature of NO as a signaling molecule in different stages can be attributed to its concentrationdependent and temporal effects that lead to different cellular effects (Vasudevan \& Thomas 2014). The steady-state intracellular $\mathrm{NO}$ concentration is in a balance between its rate of synthesis from three different nitric oxide synthase (NOS) enzyme isoforms and consumption via versatile metabolic pathways and strongly depend on the tissue oxygen concentration. $\cdot$ NO production and NOS expression are often dysregulated and associate with almost all types of malignancies with dissimilar prognosis (Vasudevan \& Thomas 2014). The regulatory function of $\cdot \mathrm{NO}$ as an epigenetic modifier is also recently recognized and harbours important implications in regulating oncogene and tumor suppressor-gene transcription (Vasudevan \& Thomas 2014). NO-derived intracellular adducts including dinitrosyl-iron complexes and higher nitrogen oxides further changes NO's cellular behavior. In this context, numerous NOS inhibitors and $\cdot$ NO-releasing drugs are tested in preclinical and clinical models to block cancer growth (Vasudevan \& Thomas 2014). The inorganic anions nitrite $\left(\mathrm{NO}_{2}{ }^{-}\right)$and nitrate $\left(\mathrm{NO}_{3}{ }^{-}\right)$are end products of $\mathrm{NO}$ metabolism, yet they are also recycled in tissues and blood to form NO and other active nitrogen oxides; hence, they are measured in blood and tissues as a marker of NO production and metabolism.

In this study, we aimed to investigate the actions of extracts of Hypericum perforatum, a widely used plant-derived supplement, on redox balance and NO metabolism in blood and tumoral tissue of mice inoculated with Ehrlich ascites carcinoma cells.

\section{Materials and Methods}

\subsection{Experimental Animals and Establishment of Tumors}

Animal studies conducted in the project were performed according to the approval of Mehmet Akif Ersoy University Experimental Animals Local Ethics Committee with an approval number of 334/2017. In the study, a total of 50 Swiss albino female mice, 12-16 weeks old, weighing between 25-40 g, which were obtained from Mehmet Akif Ersoy University Experimental Animal Production and Experimental Research Laboratory, were used. Mice were fed ad libitum under controlled conditions (12 hours dark / 12 hours light) in special polypropylene cages with 8 in the negative control group, 9 in the positive control group, and 11 in the each study group with standard rat chow and normal tap water. Formation of Solid Ehrlich tumors: Ehrlich ascites carcinoma (EAC) cells to be used in the experiment were obtained from the ascites fluid of donor mouse, which was obtained from Istanbul University Experimental Animal Unit and whose tumor was previously grown by intraperitoneal injection. Ascites fluid containing Ehrlich tumor cells was taken from the peritoneal cavity of the donor mouse with the help of an injector, and $2.5 \times 10^{6}$ EAC cells were injected subcutaneously to form solid tumors in the subjects except the healthy control group. Saline was administered subcutaneously to the subjects in the healthy control group. After EAC cells were administered, the animals were weighed and randomly divided into groups.

\subsection{Experimental Groups and Drug Treatments}

The experimental groups were as follows: Group 1: Healthy control group (without Ehrlich tumor). Group 2: Cancer control group (Ehrlich tumor formed). Group 3: Ehrlich tumor was formed and Hypericum perforatum (300 mg / kg, BW, p.o) was administered. Group 4: Ehrlich tumor was formed and Hypericum perforatum (900 mg / kg, BW, p.o) was administered. Group 5: Ehrlich tumor was formed and doxorubicin (3 $\mathrm{mg} / \mathrm{kg}$, ip) was administered. Hypericum perforatum was applied by gavage every other days until the end of the study. Doxorubicin was administered as the first dose on the 2nd day, the 2nd dose 5 days after this application (7th day after tumor application) and the 3rd dose 10 days later (12th day after the tumor application), and tumor formation was followed by palpation. Animals were sacrificed on

43 | P a g e 
the 14th day after tumor inoculation. High doses of xylazine (Rompun ${ }^{\circledR}$ ) and ketamine (Ketasol ${ }^{\circledR}$ ) were administered intramuscularly for sacrification.

Tumor tissue samples washed with $\% 0.9 \mathrm{NaCl}$ and dried. Kept -20 until analysis were performed. Blood samples were centrifuged at $2500 \mathrm{rpm}$ for 15 minutes and the serum samples were kept at $-20^{\circ} \mathrm{C}$ until the time of analysis.

\subsection{Measurement of Total Antioxidant Status (TAS), Total Oxidant Status (TOS), Nitrite and Nitrate Levels}

Nitrate/nitrite concentration was measured using a spectrophotometric method according to the Cayman Nitrate/Nitrite Colorimetric Assay Kit (780001, Cayman Chemicals, Ann Arbor, MI, United States) in the serum samples and tissue homogenisates prepared according to kit protocol.

Total Antioxidant Capacity and Total Oxidant capacity were measured with the Rel Assay (Rel Assay®, Diagnostics kits, Mega Tip, Gaziantep, Turkey) in the serum samples and tissue homogenisates prepared according the manufacturer's instructions.

\section{Statistics}

The data obtained were analyzed using the SPSS22.0 package program. Statistical control of the difference between normally distributed variables was performed by one-way analysis of variance (ANOVA). The Duncan test was used as the post-hoc test for variables where the difference between groups was significant. For each variable, it was presented as "Mean \pm Standard Mean Error" (Mean \pm $\mathrm{SD})$. All statistical analyzes were analyzed with a minimum error of $5 \%$. $\mathrm{P}<0.05$ was considered as statistically significant.

\section{Results}

When the TAS levels in serum samples were compared to the healthy control group, there was a significant decrease in the group treated with doxorubucin and in the group with tumors that were not treated. The decrease in other groups is not significant. When the TOS levels in serum samples were compared with the doxorubucin applied group, there was a significant difference between the groups in which the tumor was formed but did not receive any treatment, and the groups in which high dose $\mathrm{H}$. perforatum was applied. Serum TOS levels were lower in EAC-bearing mice in comparison to control group, and in high dose Hypericum-treated mice in comparison to control group. Serum TOS levels were higher in mice treated with low dose Hypericum or doxorubicin. In serum analysis, there was no difference between the groups in other parameters in terms of nitrite or nitrate levels. There was no difference between the groups in terms of TAS and TOS levels of tumor tissue. In tumor tissue analysis, there was a significant decrease between tissue Nitrite + Nitrate and tissue Nitrate levels in all groups (H. perforatum and doxorubucin administered) compared with the group with tumor formation but left untreated.

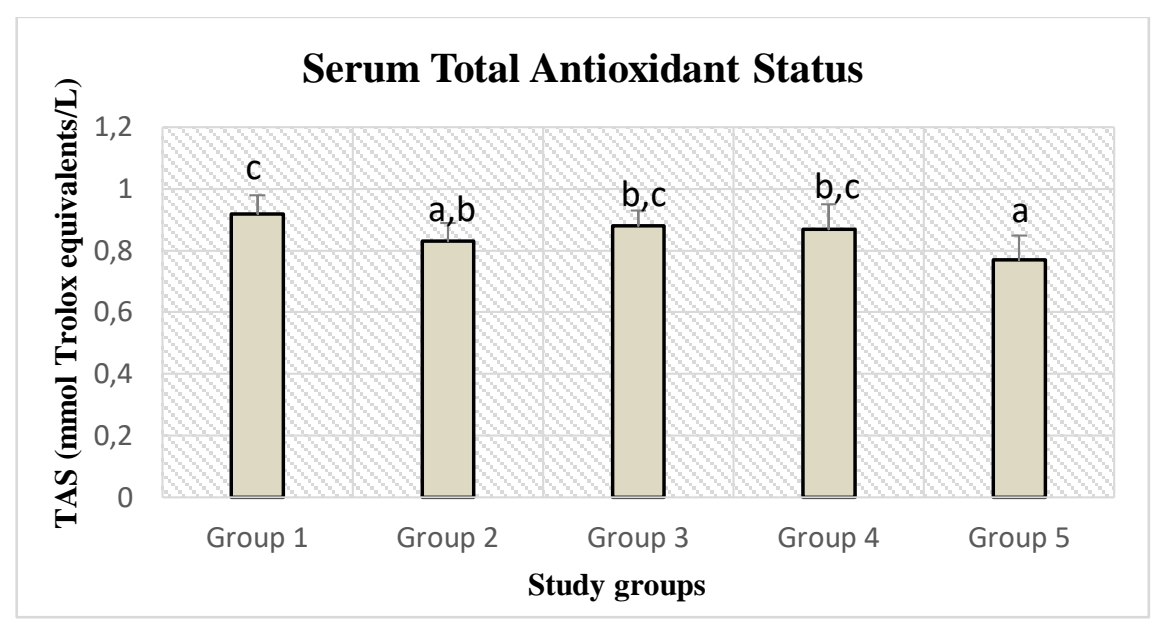

Figure 1: Serum Total Antioxidant Status in H. Perforatum applied mice with experimental breast cancer model. 


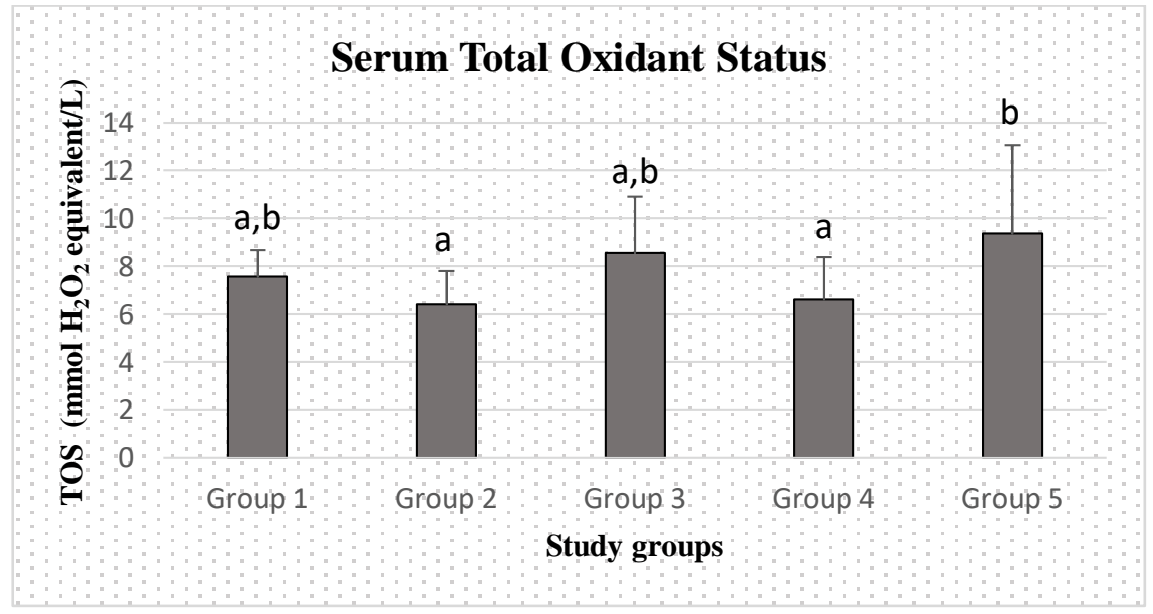

Figure 2: Serum Total Oxidant Status in H. Perforatum applied mice with experimental breast cancer model.

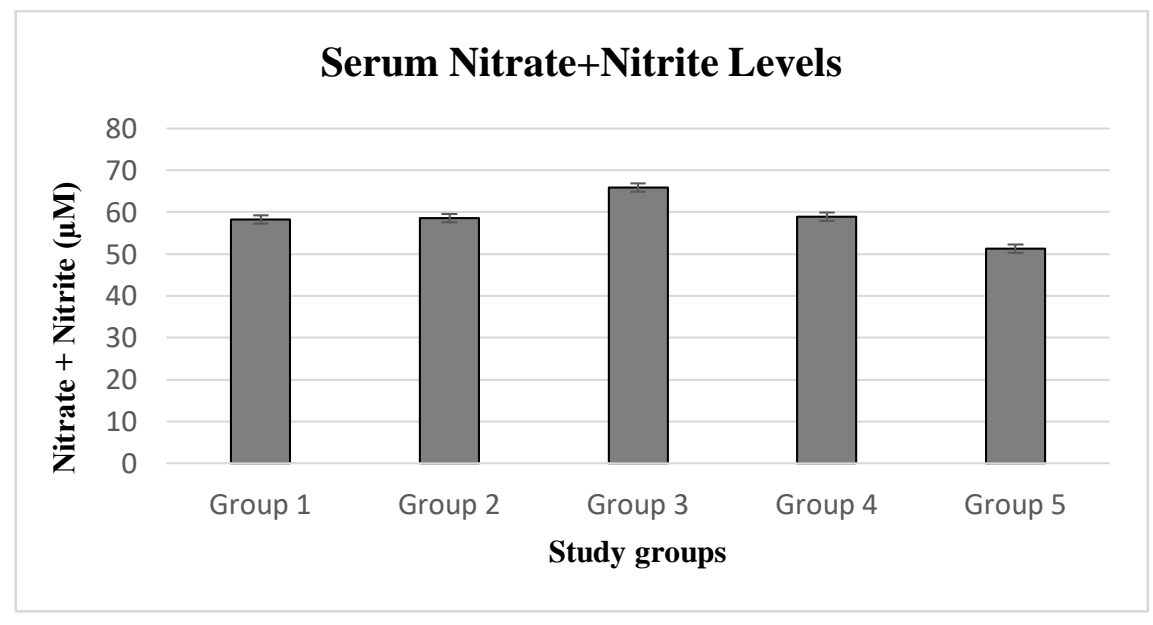

Figure 3: Serum Nitrate+Nitrite Levels in H. Perforatum applied mice with experimental breast cancer model.

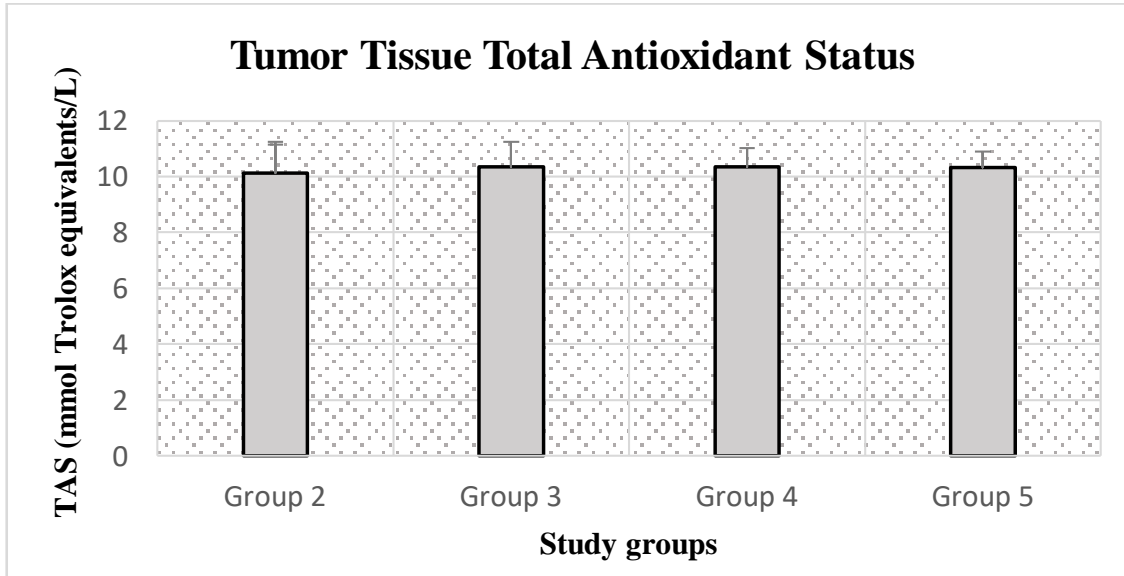

Figure 4: Tumor Tissue Total Antioxidant Status in H. Perforatum applied mice with experimental breast cancer model. 


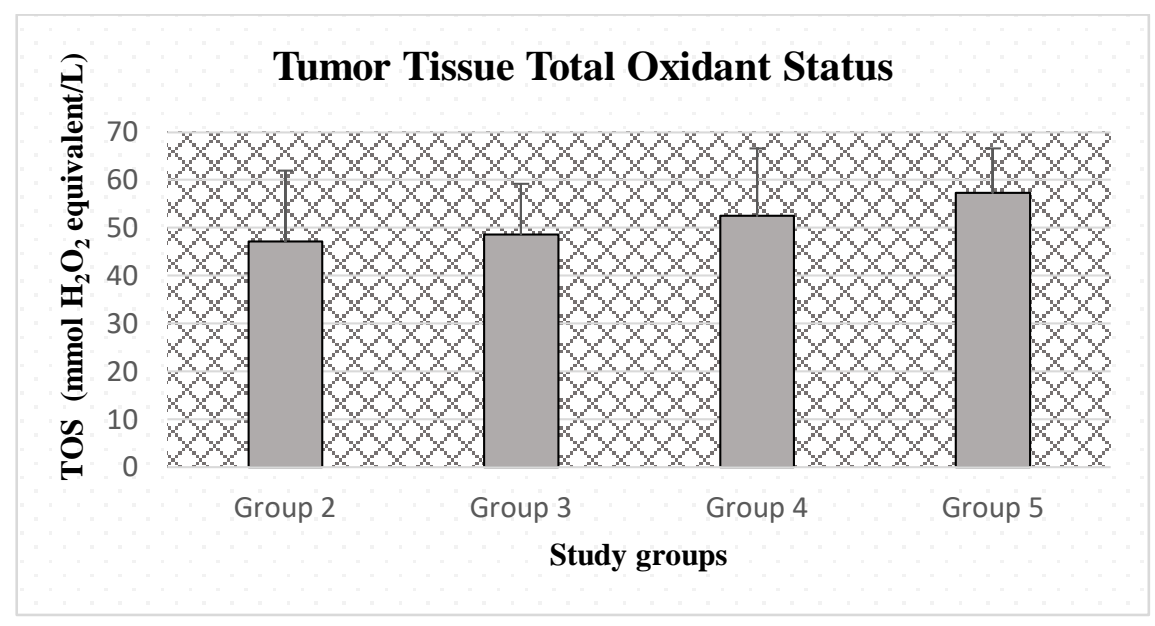

Figure 5: Tumor Tissue Total Oxidant Status in H. Perforatum applied mice with experimental breast cancer model.

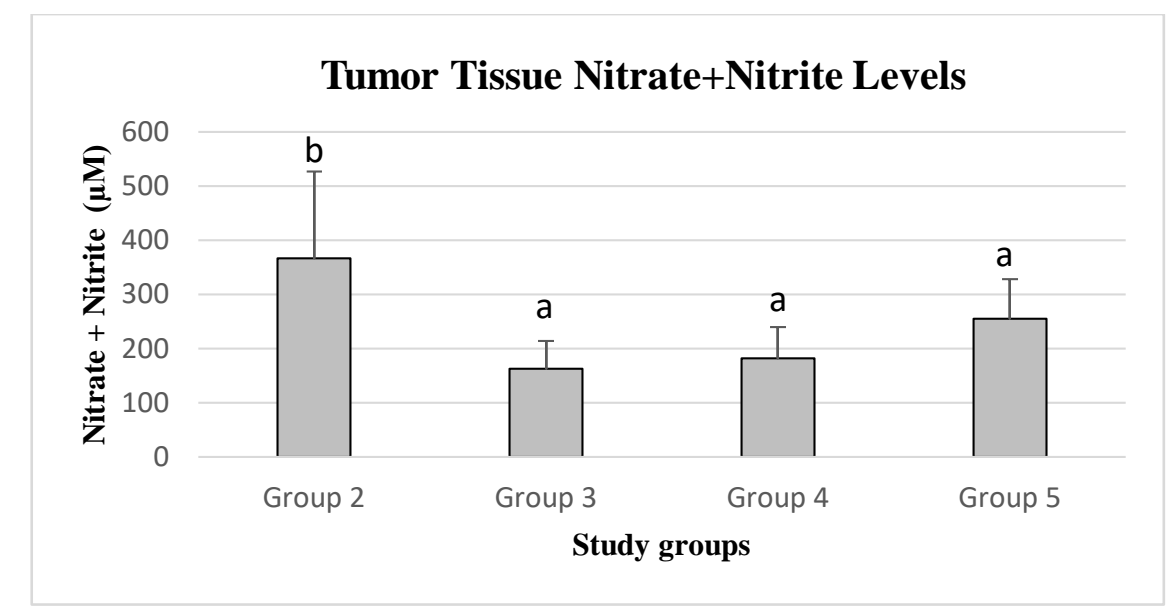

Figure 6: Tumor Tissue Nitrate+Nitrite Levels in H. Perforatum applied mice with experimental breast cancer model.

Table 1: Serum Total Antioxidant Status, Total Oxidant Status and Nitrate/Nitrite Levels in H. Perforatum applied mice with experimental breast cancer model

\begin{tabular}{ccccccc}
\hline Groups & $\mathbf{n}$ & $\begin{array}{c}\text { Serum } \\
\text { TAS }\end{array}$ & $\begin{array}{c}\text { Serum } \\
\text { TOS }\end{array}$ & $\begin{array}{c}\text { Serum } \\
\text { Nitrit+Nitrat }\end{array}$ & $\begin{array}{c}\text { Serum } \\
\text { Nitrat }\end{array}$ & $\begin{array}{c}\text { Serum } \\
\text { Nitrit }\end{array}$ \\
\hline $\mathbf{1}$ & 6 & $0,91 \pm 0,06^{\mathrm{c}}$ & $7,58 \pm 1,09^{\mathrm{a}, \mathrm{b}}$ & $58,20 \pm 14,64$ & $56,98 \pm 14,99$ & $1,21 \pm 0,77$ \\
$\mathbf{2}$ & 9 & $0,83 \pm 0,06^{\mathrm{a}, \mathrm{b}}$ & $6,43 \pm 1,39^{\mathrm{a}}$ & $58,53 \pm 8,03$ & $57,50 \pm 7,92$ & $1,03 \pm 0,29$ \\
$\mathbf{3}$ & 8 & $0,87 \pm 0,05^{\mathrm{b}, \mathrm{c}}$ & $8,57 \pm 2,34^{\mathrm{a}, \mathrm{b}}$ & $62,85 \pm 17,81$ & $61,96 \pm 17,78$ & $0,89 \pm 0,53$ \\
$\mathbf{4}$ & 9 & $0,86 \pm 0,08^{\mathrm{b}, \mathrm{c}}$ & $6,63 \pm 1,77^{\mathrm{a}}$ & $58,89 \pm 14,94$ & $58,19 \pm 14,78$ & $0,69 \pm 0,56$ \\
$\mathbf{5}$ & 8 & $0,76 \pm 0,08^{\mathrm{a}}$ & $9,37 \pm 3,70^{\mathrm{b}}$ & $51,18 \pm 7,71$ & $50,45 \pm 7,63$ & $0,73 \pm 0,27$ \\
$\mathbf{p}$ & & $*$ & $*$ & - & - & - \\
\hline
\end{tabular}


Table 2: Tumor Tissue Total Antioxidant Status, Total Oxidant Status and Nitrate/Nitrite Levels in H. Perforatum applied mice with experimental breast cancer model

\begin{tabular}{ccccccc}
\hline Groups & $\mathbf{n}$ & $\begin{array}{c}\text { Tissue } \\
\text { TAS }\end{array}$ & $\begin{array}{c}\text { Tissue } \\
\text { TOS }\end{array}$ & $\begin{array}{c}\text { Tissue } \\
\text { Nitrit+Nitrat }\end{array}$ & $\begin{array}{c}\text { Tissue } \\
\text { Nitrit }\end{array}$ & $\begin{array}{c}\text { Tissue } \\
\text { Nitrat }\end{array}$ \\
\hline $\mathbf{2}$ & 9 & $10,13 \pm 1,01$ & $47,23 \pm 14,71$ & $365,95 \pm 160,46^{\mathrm{b}}$ & $4,11 \pm 2,34$ & $361,83 \pm 161,77^{\mathrm{b}}$ \\
\hline $\mathbf{3}$ & 8 & $10,35 \pm 0,88$ & $48,57 \pm 10,69$ & $162,22 \pm 51,95^{\mathrm{a}}$ & $3,76 \pm 2,59$ & $158,45 \pm 51,29^{\mathrm{a}}$ \\
\hline $\mathbf{4}$ & 9 & $10,34 \pm 0,68$ & $52,51 \pm 14,02$ & $181,54 \pm 58,06^{\mathrm{a}}$ & $3,87 \pm 2,96$ & $177,67 \pm 58,14^{\mathrm{a}}$ \\
\hline $\mathbf{5}$ & 8 & $10,32 \pm 0,58$ & $57,27 \pm 9,355$ & $254,62 \pm 72,64^{\mathrm{a}}$ & $6,26 \pm 5,08$ & $248,36 \pm 74,98^{\mathrm{a}}$ \\
\hline
\end{tabular}

$\begin{array}{llllll}\mathbf{P} & - & - & * & *\end{array}$

\section{Discussion}

$\mathrm{NO}$ at low/intermediate to supraphysiological doses may stimulate tumor growth, while at much higher concentrations (above $300 \mathrm{nM}$ ) triggers apoptosis (Altinoz \& Elmaci 2018; Monteiro et al. 2019). Cancertolerable concentrations of NO/S-nitrosothiols (RSNOs) induce oncogenic signaling, while much higher concentrations of NO/RSNO act antitumoral (Monteiro et al. 2015). High concentrations of NO released by NO-donors could sensitize cancer cells to TRAIL via suppression of the transcription factors Yin Yang 1 (YY1) and NFkB simultaneous with upregulation of DR5 (Lee et al. 2007).

The dichotomic pro- or antitumoral features of NO depend on cellular status and redox state, local concentrations and duration of exposure, and compartmentalization of NO production (González et al. 2018). In circumstances, when its levels reach to very high concentrations, NO could arrest the cell cycle and induce apoptosis protecting against initiation and progression of cancer such as after robust release from iNOS-expressing Th1 lymphocytes and M1-polarised macrophages under highly-activated conditions (Khan et al. 2020).

But as suggested above, the actions of NO on cancer biology is biphasic and it can be proposed that the inherent nature of tumor-driven NO dominantly propagates cancer growth. In ovarian neoplasias, cyst fluid of malignant tumors contains higher levels of NO in comparison to benign lesions (Martins-Filho et al. 2017). In patients with oral precancerous and cancerous lesions, nitrite $\left(\mathrm{NO}_{2}\right)$ and nitrate $\left(\mathrm{NO}_{3}\right)$ plasma levels are higher than healthy controls (Patel et al. 2009). In lung cancer patients, increased levels of plasma nitrate very significantly associate with shorter survival (Colakogullari et al. 2006).

In animal models of breast cancer, increased expression of eNOS associates with higher invasive and metastatic features (Lala \& Orucevic 1998). NO activates EGFR (Epidermal Growth Factor Receptor) and Src via S-nitrosylation. At physiologically relevant levels, NO stimulates EGFR/Src-induced oncogenic signal pathways including $\beta$-catenin, Akt and c-Myc and the loss of the tumor suppressor activity of PP2A (Switzer et al. 2012). Moreover, NO signaling enhances EMT (Epithelial-Mesenchymal Transition), activity and expression of COX-2 (cyclooxygenase-2), and resistance to paclitaxel and adriamycin. These concerted features link NO to the formation of a stem cell-like phenotype causing the increase of STAT3 and CD44 phosphorylation (Switzer et al. 2012). NO stimulates production of the VEGF-C (Vascular Endothelial Growth Factor-C) - a stimulator of lymphangiogenesis - in human breast cancer cells in vitro (Nakamura et al. 2006). More importantly, high-grade staining with nitrotyrosine was encountered in $57.5 \%$ of the invasive breast cancers which significantly correlated with VEGF-C staining, metastasis to lymph nodes and shorter survival (Nakamura et al. 2006). In breast and colon cancer and in melanoma, supraphysiological levels of NO existing in circulating malignant cells confer them with resistance to anoikis (Monteiro et al. 2019). When the anoikis-resistant cancer cells reach to their metastatic region they undergo epithelial-mesenchymal transition. Hence, the development and employment of agents which could modify intracellular NOS concentrations may be efficient in disrupting a tumor-provoking redox homeostasis operative in malignant cells (Monteiro et al. 2019).

High NO enhances HIF-1 $\alpha$ (Hypoxia Inducible Factor- $1 \alpha$ ) protein stabilization, and activates essential cell signaling cascades, including PI3-Kinase (Phosphoinositide 3-Kinase/Protein Kinase B), MAPK (Mitogen-Activated Protein Kinase), EGFR (Epidermal Growth Factor Receptor), and Ras, via posttranslational modifications (Basudhar et al. 2017). Dysregulated NO flux in the tumor micromillieu also stimulates angiogenesis and modifies matrix metalloproteinase (MMP)/tissue inhibitor matrix metalloproteinase (TIMP)-axis associated with cancer progression (Basudhar et al. 2017). Agents reducing NO in tumors do not just reduce angiogenesis but also tumoral edema (Morbidelli et al. 2004).

47 I P a g e

www.iiste.org 
Considering that peritumoral edema is a significant factor in tumor-associated morbidity and mortality in brain tumors; NO-reducing agents may be especially efficient in brain tumor. In triple-negative breast cancer, co-expression of COX2 and NOS2 is a strong prognostic indicator which produce PGE 2 and NO, respectively, and can act in both a paracrine and an autocrine manner (Basudhar et al. 2019). Aberrations of their physiological regulation change intercellular communication of cancer cells with the immune cells and involve in tumoral cell adaptation to the hypoxic tumor microenvironment (Basudhar et al. 2019). In patients with pancreatic ductal adenocarcinoma (PDAC) whose tumors are resected at an early stage, higher expression of NOS2/iNOS in tumor tissues associate with shorter survival (Wang \& Hussain 2017). Additionally, deletion of NOS2 by genetic targeting increased survival in mice with autochthonous PDAC. Furthermore, targeting NOS3/eNOS (endothelial-Nitric Oxide Synthase) lowered precursor lesions of PDAC in mice, which trended toward longer survival (Wang \& Hussain 2017).

In sum, a detailed and comprehensive survey of the scientific literature suggest that tumor-driven NO is mostly propagating the initiation and progression of cancer; and hence, agents which would reduce NO and its metabolites within malignant tissues may be helpful in controlling cancer growth. As will be outlined below, Hypericum perforatum plant extracts and their purified chemical constituents may be very efficient in reducing tumoral NO levels as they were shown to reduce NO in versatile pathological conditions.

In zymosan-induced multiple organ dysfunction syndrome in mice, Hypericum perforatum extract treatment ameliorates multisystem inflammation and organ failure, which was accompanied with reduced immunoexpression of iNOS/NOS2 and lesser staining with nitrotyrosine in lung and intestine tissues (Di Paola et al. 2007).

In mice models, hypericin alleviates severity of Alzheimer's Disease and inhibits oligomeric amyloid protein A 342 -induced activation of iNOS/NOS2 in microglia in vitro (Zhang et al. 2016). Hypericum perforatum extract reduces caffeine induced stimulation of locomotor activity which was attributed to its efficacy to reduce NOS expression in the central nervous system (Uzbay et al. 2007). Luo et al. examined the inhibitory actions of six flavonoids from Hypericum perforatum on NOS activity in cerebral homogenates and blood of rats (Luo et al. 2004). Of the investigated constituents, hyperoside and quercetin exerted concentration-dependent inhibition on NOS. The $\mathrm{IC}_{50}$ values of hyperoside for inhibiting NOS in rat blood and cerebral homogenate were 158.49 and 56.23 and microM, respectively; the same values for quercetin were 57.54 and 63.06 microM, respectively (Luo et al. 2004). On the other hand, total extracts of Hypericum perforatum exert inhibitory effects on NOS on much reduced concentrations suggesting that Hypericum perforatum includes other undefined ingredients which could increase its potency to inhibit NO production. Kraus et al. employed BV2 and N11 mouse microglia and RAW 264.7 macrophages to determine the actions of Hypericum perforatum extract and constituents thereof on production of NO production (Kraus et al. 2010). They revealed that Hypericum perforatum extracts effectively inhibited lipopolysaccharide-induced release of $\mathrm{NO}$ and determined hyperforin as the responsible ingredient, being effective at levels between 0.25 and 0.75 microM (Kraus et al. 2010). The reduction of NO production occured by decreased iNOS/NOS2 expression on the protein and mRNA level. Lastly, they observed that these actions associated with a suppression of the NFkB and phosphoCREB activation (Kraus et al. 2010). On the other, there also exist data that Hypericum perforatum extracts exert anticonvulsant effects in mice, which was inhibited with the NOS-inhibitor L-NAME (Hosseinzadeh et al. 2005).

\section{Conclusions}

Cancer remains to be one of the main causes of death and metastatic malignant disease is a devastating health problem globally. Inflammation, oxidative stress and enhanced NO production produce selfpropagating viscious cycles which all converge to stimulate cancer growth. Therefore, supplements which would reduce all these 3 cascades would be excellent candidates to control malignant growth. Although, it shall be also emphasized that the usage of antioxidant compounds together with chemo- or radiotherapy may be harmful as these classical treatment modalities kill cancer cells via reactive oxygen species and nitrosative stress (excess production of NO). Hence, antioxidant and anti-nitrosative compounds shall be used between intervals of guideline-advised treatment modalities and/or after finishing of these treatments. Hypericum perforatum extracts deserve to be studied further in terms of diminishing procancerous inflammation, oxidative and nitrosative stress. 


\section{References}

Altinoz, M.A., Elmaci, İ. (2018). Targeting nitric oxide and NMDA receptor-associated pathways in treatment of high grade glial tumors. Hypotheses for nitro-memantine and nitrones. Nitric Oxide, 1;79, 68-83. doi: 10.1016/j.niox.2017.10.001

Azad, N., Iyer, A., Vallyathan, V., Wang, L., Castranova, V., Stehlik, C., Rojanasakul, Y. (2010). Role of oxidative/nitrosative stress-mediated Bcl-2 regulation in apoptosis and malignant transformation. Ann N Y Acad Sci, 1203, 1-6. doi: 10.1111/j.1749-6632.2010.05608.x

Basudhar, D., Bharadwaj, G., Somasundaram, V., Cheng, R.Y.S., Ridnour, L.A., Fujita, M., Lockett, S.J., Anderson, S.K., McVicar, D.W., Wink, D.A. (2019). Understanding the tumour microenvironment communication network from an NOS2/COX2 perspective. Br J Pharmacol, 176(2), 155-176. doi: 10.1111/bph. 14488

Basudhar, D., Somasundaram, V., de Oliveira, G.A., Kesarwala, A., Heinecke, J.L., Cheng, R.Y., Glynn, S.A., Ambs, S., Wink, D.A., Ridnour, L.A. (2017). Nitric Oxide Synthase-2-Derived Nitric Oxide Drives Multiple Pathways of Breast Cancer Progression. Antioxid Redox Signal, 26(18), 1044-1058. doi: 10.1089/ars.2016.6813

Blank, M., Mandel, M., Hazan, S., Keisari, Y., Lavie, G. (2001). Anti-cancer activities of hypericin in the dark. Photochem Photobiol, 74(2), 120-5. doi: 10.1562/00318655(2001)074<0120:acaohi>2.0.co;2

Cinci, L., Di Cesare Mannelli, L., Maidecchi, A., Mattoli, L., Ghelardini, C. (2017). Effects of Hypericum perforatum extract on oxaliplatin-induced neurotoxicity: in vitro evaluations. $Z$ Naturforsch C J Biosci, 1;72(5-6), 219-226. doi: 10.1515/znc-2016-0194

Colakogullari, M., Ulukaya, E., Yilmaztepe, A., Ocakoglu, G., Yilmaz, M., Karadag, M., Tokullugil, A. (2006). Higher serum nitrate levels are associated with poor survival in lung cancer patients. Clin Biochem, 39(9), 898-903. doi: 10.1016/j.clinbiochem.2006.06.008.

Di Paola, R., Mazzon, E., Muià, C., Crisafulli, C., Genovese, T., Di Bella, P., Esposito, E., Menegazzi, M., Meli, R., Suzuki, H., Cuzzocrea, S. (2007). Protective effect of Hypericum perforatum in zymosan-induced multiple organ dysfunction syndrome: relationship to its inhibitory effect on nitric oxide production and its peroxynitrite scavenging activity. Nitric Oxide, 16(1), 118-30. doi: 10.1016/j.niox.2006.05.006

González, R., Molina-Ruiz, F.J., Bárcena, J.A., Padilla, C.A., Muntané J. (2018). Regulation of Cell Survival, Apoptosis, and Epithelial-to-Mesenchymal Transition by Nitric Oxide-Dependent PostTranslational Modifications. Antioxid Redox Signal, 1;29(13), 1312-1332. doi: 10.1089/ars.2017.7072

Hohmann, M.S., Cardoso, R.D., Fattori, V., Arakawa, N.S., Tomaz, J.C., Lopes, N.P., Casagrande, R., Verri, W.A. Jr. (2015). Hypericum perforatum Reduces Paracetamol-Induced Hepatotoxicity and Lethality in Mice by Modulating Inflammation and Oxidative Stress. Phytother Res, 29(7), 1097 101. doi: $10.1002 /$ ptr.5350

Hosseinzadeh, H., Karimi, G.R., Rakhshanizadeh, M. (2005). Anticonvulsant effect of Hypericum perforatum: role of nitric oxide. J Ethnopharmacol, 98(1-2), 207-8. doi: 10.1016/j.jep.2004.12.007

Huntosova, V., Novotova, M., Nichtova, Z., Balogova, L., Maslanakova, M., Petrovajova, D., Stroffekova, K. (2017). Assessing light-independent effects of hypericin on cell viability, ultrastructure and metabolism in human glioma and endothelial cells. Toxicol In Vitro, 40, 184-195. doi: 10.1016/j.tiv.2017.01.005 
Iyer, A.K., Rojanasakul, Y., Azad, N. (2014). Nitrosothiol signaling and protein nitrosation in cell death. Nitric Oxide, 42, 9-18. doi: 10.1016/j.niox.2014.07.002

Khan, F.H., Dervan, E., Bhattacharyya, D.D., McAuliffe, J.D., Miranda, K.M., Glynn, S.A. (2020). The Role of Nitric Oxide in Cancer: Master Regulator or Not? Int J Mol Sci. 21(24), 9393. doi: $10.3390 /$ ijms 21249393

Kraus, B., Wolff, H., Elstner, E.F., Heilmann, J. (010). Hyperforin is a modulator of inducible nitric oxide synthase and phagocytosis in microglia and macrophages. Naunyn Schmiedebergs Arch Pharmacol, 381(6), 541-53. doi: 10.1007/s00210-010-0512-y

Lala, P.K., Orucevic, A. (1998). Role of nitric oxide in tumor progression: lessons from experimental tumors. Cancer Metastasis Rev, 17(1), 91-106. doi: 10.1023/a:1005960822365

Lee, J.Y., Huerta-Yepez, S., Vega, M., Baritaki, S., Spandidos, D.A., Bonavida, B. (2007). The NO TRAIL to YES TRAIL in cancer therapy (review). Int J Oncol, 31(4), 685-91

Luo, L., Sun, Q., Mao, Y.Y., Lu, Y.H., Tan, R.X. (2004). Inhibitory effects of flavonoids from Hypericum perforatum on nitric oxide synthase. J Ethnopharmacol, 93(2-3), 221-5. doi: 10.1016/j.jep.2004.03.042

Martins-Filho, A., Jammal, M.P., Micheli, D.C., Tavares-Murta, B.M., Etchebehere, R.M., Murta, E.F.C., Nomelini, R.S. (2017). Role of Intracystic Cytokines and Nitric Oxide in Ovarian Neoplasms. Scand J Immunol, 86(6), 462-470. doi: 10.1111/sji.12617

Menegazzi, M., Masiello, P., Novelli, M.. (2020). Anti-Tumor Activity of Hypericum perforatum L. and Hyperforin through Modulation of Inflammatory Signaling, ROS Generation and Proton Dynamics. Antioxidants (Basel), 10(1), 18. doi: 10.3390/antiox10010018

Monteiro, H.P., Costa, P.E., Reis, A.K., Stern, A. (2015). Nitric oxide: Protein tyrosine phosphorylation and protein S-nitrosylation in cancer. Biomed J, 38(5), 380-8. doi: 10.4103/23194170.158624.

Monteiro, H.P., Rodrigues, E.G., Amorim Reis, A.K.C., Longo, L.S. Jr, Ogata, F.T., Moretti A.I.S., da Costa, P.E., Teodoro, A.C.S., Toledo, M.S., Stern, A. (2019). Nitric oxide and interactions with reactive oxygen species in the development of melanoma, breast, and colon cancer: A redox signaling perspective. Nitric Oxide, 89, 1-13. doi: 10.1016/j.niox.2019.04.009

Morbidelli, L., Donnini, S., Ziche, M. (2004). Role of nitric oxide in tumor angiogenesis. Cancer Treat Res, 117, 155-67. doi: 10.1007/978-1-4419-8871-3_11

Nakamura, Y., Yasuoka, H., Tsujimoto, M., Yoshidome, K., Nakahara, M., Nakao, K., Nakamura, M., Kakudo, K. (2006). Nitric oxide in breast cancer: induction of vascular endothelial growth factor-C and correlation with metastasis and poor prognosis. Clin Cancer Res. 2006 Feb 15;12(4):1201-7. doi: 10.1158/1078-0432.CCR-05-1269

Patel, J.B., Shah, F.D., Shukla, S.N., Shah, P.M., Patel, P.S. (2009). Role of nitric oxide and antioxidant enzymes in the pathogenesis of oral cancer. J Cancer Res Ther, 5(4), 247-53. doi: $10.4103 / 0973-1482.59898$

Switzer, C.H., Glynn, S.A., Cheng, R.Y., Ridnour, L.A., Green, J.E., Ambs, S., Wink, D.A. (2012). Snitrosylation of EGFR and Src activates an oncogenic signaling network in human basal-like breast cancer. Mol Cancer Res, 10(9), 1203-15. doi: 10.1158/1541-7786.MCR-12-0124 
Tedeschi, E., Menegazzi, M., Margotto, D., Suzuki, H., Förstermann, U., Kleinert, H. (2003). Antiinflammatory actions of St. John's wort: inhibition of human inducible nitric-oxide synthase expression by down-regulating signal transducer and activator of transcription-1alpha (STAT1alpha) activation. J Pharmacol Exp Ther, 307(1), 254-61. doi: 10.1124/jpet.103.054460

Uzbay, I.T., Coskun, I., Kayir, H., Ozturk, N., Ozturk, Y. (2007). Extract of Hypericum perforatum blocks caffeine-induced locomotor activity in mice: a possible role of nitric oxide. Phytother Res, 21(5), 415-9. doi: 10.1002/ptr.2085

Vasudevan, D., Thomas, D.D. (2014). Insights into the diverse effects of nitric oxide on tumor biology. Vitam Horm, 96, 265-98. doi: 10.1016/B978-0-12-800254-4.00011-8

Wang, J., Hussain, S.P. (2017). NO ${ }^{\bullet}$ and Pancreatic Cancer: A Complex Interaction with Therapeutic Potential. Antioxid Redox Signal, 26(17), 1000-1008. doi: 10.1089/ars.2016.6809

Yang, Y., Tantai, J., Sun, Y., Zhong, C., Li, Z. (2017). Effect of hyperoside on the apoptosis of A549 human non-small cell lung cancer cells and the underlying mechanism. Mol Med Rep, 16(5), 64836488. doi: 10.3892/mmr.2017.7453

Zhang, M., Wang, Y., Qian, F., Li, P., Xu, X. (2016). Hypericin inhibits oligomeric amyloid $\beta 42-$ induced inflammation response in microglia and ameliorates cognitive deficits in an amyloid $\beta$ injection mouse model of Alzheimer's disease by suppressing MKL1. Biochem Biophys Res Commun, 481(1-2), 71-76. doi: 10.1016/j.bbrc.2016.11.016 